\title{
Revisiting Contribution Analysis
}

\section{John Mayne}

\begin{abstract}
The basic ideas behind contribution analysis were set out in 2001. Since then, interest in the approach has grown and contribution analysis has been operationalized in different ways. In addition, several reviews of the approach have been published and raise a few concerns. In this article, I clarify several of the key concepts behind contribution analysis, including contributory causes and contribution claims. I discuss the need for reasonably robust theories of change and the use of nested theories of change to unpack complex settings. On contribution claims, I argue the need for causal narratives to arrive at credible claims, the limited role that external causal factors play in arriving at contribution claims, the use of robust theories of change to avoid bias, and the fact that opinions of stakeholders on the contribution made are not central in arriving at contribution claims.
\end{abstract}

Keywords: causal factors, causal narratives, contribution analysis, contribution claims, contributory causes, theories of change

Résumé : Les principes fondamentaux de l'analyse de contribution ont été établis en 2001. Depuis lors, l'intérêt porté à cette approche a crû et l'analyse de contribution a été opérationnalisée de différentes façons. De plus, plusieurs examens de cette approche ont été publiés et ont soulevé quelques inquiétudes. Dans cet article, je clarifie plusieurs concepts de lanalyse de contribution, incluant les causes contributives et les énoncés de contribution. Je discute de la nécessité de faire appel à des théories $d u$ changement raisonnablement robustes et d'utiliser des théories complémentaires $d u$ changement pour comprendre des contextes complexes. Au chapitre des énoncés de contribution, je soutiens qu'il est nécessaire d'élaborer des narratifs causaux pour arriver à des attributions crédibles; que les facteurs causaux externes jouent un rôle limité dans l'atteinte des énoncés de contribution; que l'utilisation de théories du changement robustes permet d'éviter les biais; et que les opinions des intervenant.e.s sur la contribution ne devraient pas jouer un rôle central dans l'établissement des énoncés de contribution.

Mots clé : facteurs causaux, narratifs causaux, analyse de contribution, attributions de contribution, causes contributives, théories du changement

Increasingly, interventions that evaluators are asked to assess are quite complicated and complex. They may involve a number of major components, different levels of government and/or numerous partners, and have a long timeframe, perhaps with

Corresponding author: John Mayne, john.mayne@rogers.com

(c) 2019 Canadian Journal of Program Evaluation / La Revue canadienne d'évaluation de programme 34.2 (Fall / automne), 171-191 doi: 10.3138/cjpe.68004 
emerging outcomes (Byrne, 2013; Gerrits \& Verweij, 2015; Schmitt \& Beach, 2015). Nevertheless, funders of such interventions still want to know if their funding has made a difference-if the interventions have improved the lives of people-and in what manner. While a range of evaluation approaches might address these questions, theory-based methods are often used, including contribution analysis (Befani \& Mayne, 2014; Befani \& Stedman-Bryce, 2016; Mayne, 2001, 2011, 2012; Paz-Ybarnegaray \& Douthwaite, 2016; Punton \& Welle, 2015; Stern et al., 2012; Wilson-Grau \& Britt, 2012).

Contribution analysis (CA) has continued to evolve since its introduction in 2001 (Budhwani \& McDavid, 2017; Dybdal, Nielsen, \& Lemire, 2010). It was first presented in the setting of using monitoring data to say something about causal issues related to an intervention. Since then, most thinking about and application of CA has been as an evaluation approach to get at causal issues and understanding about how change is brought about. At the same time, my concepts and ideas about theories of change-the basic tool used for CA-have evolved considerably (Mayne, 2015, 2017, 2018). In this article, I would like to set out my current thinking on several key issues and some misunderstandings around CA:

- how causality is understood and addressed in CA,

- useful theories of change for CA in complex settings,

- inferring causality for contribution claims, and

- generalizing CA findings on contribution claims.

Those using or reviewing contribution analysis have raised several concerns about its application (Budhwani \& McDavid, 2017; Delahais \& Toulemonde, 2012, 2017; Dybdal et al., 2010; Lemire, Nielsen, \& Dybdal, 2012; Schmitt \& Beach, 2015). I will address these concerns and issues as the article unfolds. The article aims to correct a number of misinterpretations around CA. It builds on several previous publications and assumes some working knowledge of CA.

First, here is a review of the terms being used:

- Impact pathways describe causal pathways showing the linkages between a sequence of steps in getting from activities to impact.

- A theory of change (ToC) adds to an impact pathway by describing the causal assumptions behind the links in the pathway-what has to happen for the causal linkages to be realized.

- Causal link assumptions are the events or conditions necessary or likely necessary for a particular casual link in a ToC pathway to be realized.

- Results are the outputs, outcomes, and impacts associated with an intervention.

A discussion of these terms can be found in Mayne (2015). It should be noted that these terms are not always defined or used by others as set out above, and indeed there is no universal agreement on them. It is important, therefore, to define carefully how the terms are being used in a particular setting. 


\section{A BRIEF OVERVIEW OF CONTRIBUTION ANALYSIS}

Contribution analysis is an approach for addressing causality, producing credible claims about the intervention as a contributory cause (Mayne, 2011, 2012). As such, it explores how and why interventions are working and for whom. Contribution analysis is increasingly being used in evaluations (Buckley, 2016; Buregeya, Brousselle, Nour, \& Loignon, 2017; Delahais \& Toulemonde, 2017; Downes, Novicki, \& Howard, 2018; Kane, Levine, Orians, \& Reinelt, 2017; Noltze, Gaisbauer, Schwedersky, \& Krapp, 2014; Ton, 2017), and in particular to address causal issues in complex settings (Koleros \& Mayne, 2019; Palladium, 2015).

The basis of the contribution claim is the empirical evidence confirming a solid $\mathrm{ToC}$ of an intervention, that is, confirming the impact pathways, the assumptions behind the causal links in the $\mathrm{ToC}$, and the related causal narratives explaining how causality is inferred. The $\mathrm{ToC}$ is the outline for the contribution story of the intervention. The steps usually undertaken in contribution analysis are shown in Box 1 (Mayne, 2011).

\section{Box 1. Steps in contribution analysis}

Step 1: Set out the specific cause-effect questions to be addressed

Step 2: Develop robust theories of change for the intervention and its pathways

Step 3: Gather the existing evidence on the components of the theory of change model of causality:

- The results achieved

- The causal link assumptions realized

Step 4: Assemble and assess the resulting contribution claim, and the challenges to it

Step 5: Seek out additional evidence to strengthen the contribution claim

Step 6: Revise and strengthen the contribution claim

Step 7: Return to Step 4 if necessary

\section{KEY CONCEPTS IN CAUSALITY AND CONTRIBUTION ANALYSIS}

Causality is always a key element of an evaluation, and hence what perspective to take on causality is important. Contribution analysis-and other theory-based evaluation approaches - uses a generative view of causality, talking of causal packages and contributory causes.

\section{Generative Causality}

In many situations a counterfactual perspective on causality-which is the traditional evaluation perspective-is unlikely to be useful; experimental designs are 
often neither feasible nor practical. Rather, a more useful perspective is that of generative causality: ${ }^{1}$ seeing causality as a chain of cause-effect events (Gates \& Dyson, 2017, p. 36; Pawson \& Tilley, 1997). This is what we see with models of interventions: a series or several series of causal steps-impact pathways-between the activities of the intervention and the desired impacts. Taking the generative or this stepwise perspective on causality and setting out an impact or contribution pathway is essential in understanding and addressing the contribution made by the intervention. The associated ToC model sets out what is needed if the expected results are to be realized.

\section{Contributory Causes}

Contribution analysis aims at arriving at credible claims on the intervention as a contributory cause, namely, that the intervention was one of several necessary or likely necessary ${ }^{2}$ factors in a causal package that together brought about or contributed to the changes observed (Cartwright \& Hardie, 2012; Mackie, 1974; Mayne, 2012). That is, it is this causal package of factors that will bring about change, and all of these factors are necessary to bring about the change-they are all INUS conditions ${ }^{3}$ - and hence in a logical sense all are of equal importance. In more complex settings, interventions may comprise a number of different components, and for each, one can ask if the component was a contributory cause.

Contribution analysis uses this stepwise perspective on causality to assess whether the intervention has "made a difference," which in this context means that the intervention had a positive impact on people's lives-that is, it made a contribution, it played a causal role. And it did so because it was a necessary part of a causal package that brought about or contributed to change. This interpretation of making a difference needs to be distinguished from the meaning associated with the counterfactual perspective on causality, where "made a difference" means "what would have happened without the intervention." This concept of a contributory cause responds to the question posed by Budhwani and McDavid (2017) on the specific meaning of a contribution within CA.

\section{Contribution Claims}

Contribution claims have been discussed in previous articles (Mayne, 2011, 2012). But some elaboration and extension is needed. Contribution claims are not just about whether the intervention made a contribution or not. Certainly, a key contribution claim is the yes/no evaluation question:

1. Has the intervention (or component) made a difference? Has it played a positive causal role in bringing about change?

But a more interesting and important contribution claim is around this evaluation question: 
2. How and why has the intervention (or component) made a difference, or not, and for whom?

The contribution claim here is about the intervention (or an intervention component) causal package at work. How and in what manner did the intervention support factors and the intervention efforts bring about, or contribute to, change? The contribution claim provides the evidence on why change occurred, that is, the causal narrative. It might also explain why the expected change was not realized, why the intervention did not make a difference.

\section{Demonstrating Contribution Claims}

As noted above, the basis for contribution analysis is the intervention ToC, and verifying the ToC-the results, the assumptions, and the causal links-with empirical evidence.

Several authors have suggested that in contribution analysis, contribution claims are indeed based on opinions. Schmitt and Beach (2015, p. 436) claim that " $\mathrm{i}] \mathrm{n}$ CA, stakeholders [being] interviewed to find out whether they believe the program worked" is the basis for contribution claims. However, this is not what CA is about at all. The aim of contribution analysis is to get beyond basing a contribution claim on opinions of stakeholders about the contribution made. Interviews may be conducted as part of the process to gather information on the results achieved and if assumptions were realized, but basing contribution claims on opinions about the claims is not part of the process. Rather, the evidence gathered on the ToC is used to analyze and make conclusions about contribution claims. Any reports or articles that rely solely on opinions are not reporting on a CA, despite what their authors may claim. Such studies should have a different label to remove references to actual CA.

A second issue related to contribution claims focuses on the role of external factors in arriving at a credible contribution claim. There is indeed some confusion over the role of external influences and especially alternative or rival explanations in CA, confusion that I have contributed to. In Mayne (2011), I suggested that a contribution claim could be made when external factors were shown not to have contributed significantly, and in Mayne (2012), I raised the need to explore rival explanations. These statements were incorrect in that they did not fully recognize the implication of having multiple causal factors at work, some of which may be associated with the intervention and others with external influences. However, external causal factors are usually not alternative or rival explanations. They are simply other causal factors at work.

Therefore, in my view, the "alternative" and "rival" terms are inappropriate in the context of complex causality. But there is a more important implication, namely, that one can explore whether or not a causal factor in a causal package made a contribution and how it did so without considering the other causal factors at play, outside the package, such as external influences, except of course if they are causally linked. A robust ToC sets out the intervention as a contributory cause. Empirically verifying the ToC allows the contribution claim to be made. 
Budhwani and McDavid (2017, p. 4) write that "[CA] relies on tests of alternative explanations to act as substitute candidates in place of counterfactuals to determine the plausibility of a proposed theory of change." As discussed above, this is not the case, and of course CA uses a stepwise (generative) not a counterfactual approach to causality. Lemire et al. (2012) also argue for the need to examine alternative or rival explanations to prove plausible association. Again, this is not correct, but in this case the authors seem to realize this in a footnote, saying that examining alternative explanations is only needed if the aim is to compare the relative contribution of the intervention. And that is true, although I would still argue that the alternative/rival explanations terminology is misleading, since all such factors may be contributing to the results: they are not rivals or alternatives.

The extent to which an evaluation explores the causal factors other than the intervention depends of course on the evaluation question being addressed. If the evaluation question is about assessing what brought about an observed impact, then these other factors would indeed need to be explored. If addressing the narrower question of whether the intervention made a contribution to the impact and how it did so, then these other factors need not play a major role in the analysis (Befani \& Mayne, 2014).

If an analysis uses a weak ToC with insufficient causal link assumptions, then a credible contribution claim based on this ToC is not possible. In this case, exploring other external influences might allow some conclusions to be reached concerning the intervention; however, this approach is not CA as discussed in this article.

\section{MEANINGFUL CONTRIBUTION QUESTIONS}

Step 1 in contribution analysis (Box 1) is setting out the causal questions to be addressed in the analysis. This is an important first step that is often not adequately addressed. The challenge here is that it is relatively easy to set out evaluation causal questions that sound reasonable and meaningful-such as "Has the intervention been effective?"- but are actually not. The basic reason is that most interventions on their own are not the cause of observed results (Mayne, forthcoming). The focus in CA is on the contribution an intervention is making to an expected result. Thus, (1) the particular result(s) of interest need(s) to be clearly specified, and (2) CA is not trying to explain what brought about the result, but rather if and how the intervention made a contribution. Therefore, for example, as discussed above, the need to explore other influencing factors depends on just what the causal question is.

\section{USEFUL THEORIES OF CHANGE}

\section{The Need in CA for Robust ToCs}

Previous articles (Mayne, 2001, 2011, 2012) on contribution analysis generally assume that the ToC used is reasonably detailed and sound, although they do not elaborate. However, using a weak ToC in a contribution analysis can only lead to weak contribution analysis findings. 
I have suggested criteria for robust theories of change, based on the ToC being both structurally sound and plausible. The detailed criteria, drawn in part from Davies (2012), are discussed in Mayne (2017) for all elements of a ToC: each result, each assumption, each causal link, and overall. For example, if the ToC is not understandable, the causal links in the model cannot be confirmed or, if seemingly "confirmed," would not lead to credible causal claims. Similarly, if terms are ambiguous, the specific results cannot be empirically confirmed.

As a result of this expanded thinking, Step 2 in Box 1 now highlights the need for a robust theory of change. However, the full set of the robust criteria is quite demanding, and the aim is often to ensure that a reasonably robust ToC is available for contribution analysis. The proposed criteria can support this analysis and help strengthen the ToC. In addition, a good ToC should be supported as much as possible by prior social science research and evidence. This type of support will help build credible causal narratives.

Both Budhwani and McDavid (2017) and Delahais and Toulemonde (2012) raise concerns about bias in arriving at contribution claims. I would argue that if one is using a reasonably robust $\mathrm{ToC}$ and empirically confirming it in a $\mathrm{CA}$, then the likelihood of bias is greatly reduced, when all of the necessary assumptions associated with each causal link in the $\mathrm{ToC}$ are confirmed with empirical evidence. And, of course, if, as Delahais and Toulemonde (2012) argue, one is able to use more than one source of data for the verification, then the chance of any bias is even further reduced. Remember that one is not simply looking to confirm a yes/ no issue of contribution but probably, more importantly, from the collection of verified assumptions building a credible causal narrative on how and why the intervention contributed, and for whom.

Some have questioned the need for the "necessity" of causal link assumptionsa robust criterion, noting, in particular, that assumptions are often not $0-1$ variables but stated as conditions that could be partially met. What then does necessity mean for a partially met assumption? Results in most ToCs are not defined as a specific amount of the result. Consider an intervention aimed at educating mothers about the benefits of a nutritious diet for their children (see White, 2009, for a discussion of such an intervention). One result here would be "mothers adopt new feeding practices," and a related assumption could be "supportive husbands and mother-inlaw." Then a partially met assumption (somewhat supportive) would mean less of the result (adopting some practices) but one that is still necessary to get that result.

For a robust $\mathrm{ToC}$, it is always better to define the result as clearly as possible, such as, for example, "fully adopting new practices" to relate better to the causal link assumptions. It is still the case that if the assumption is not realized at all, then there will be no result.

\section{Unpacking Complex Intervention Settings: Different ToCs for Different Purposes}

It should be evident that there is not a unique representation of a theory of change for a given intervention, so deciding on how much detail to include can 
be a challenge. In most cases, several different depictions of a theory of change are needed to meet different purposes (Mayne, 2015). Further, ToCs can quickly become overly complicated and less useful if too much detail is used in any one representation. In Mayne (2015), several levels of ToCs are presented and their uses discussed to help with this problem:

- A narrative ToC describes briefly how the intervention is intended to work.

- The overview ToC indicates the various pathways to impact that comprise the intervention showing some of steps in each pathway along the way to impact. It can also set out the rationale assumptions or premises behind the intervention, but usually not the causal link assumptions.

- Nested ToCs are developed to unpack a more complicated/complex intervention and include the explicit causal link assumptions. There can be a nested ToC, for example, for each pathway, for each pathway in a different geographical area, and/or for different targeted reach groups. Koleros and Mayne (2019) discuss using nested ToCs for different actor groups for a complex police reform intervention.

Budhwani and McDavid (2017, p. 19) suggest that CA may not work well in complex settings due to the difficulty of building useful ToCs in such a context. Actual experience is quite the opposite. Using nested ToCs to unpack a complex intervention and its context has worked well in numerous situations (see, for example, Douthwaite, Mayne, McDougall, \& Paz-Ybarnegaray (2017); Koleros \& Mayne (2019); Mayne \& Johnson (2015); Riley et al. (2018).

\section{The Need for Evaluable ToC Models}

Usually, the evaluator needs to develop or guide the development of ToCs that can be used for evaluation purposes. Often, the evaluator finds an already developed ToC of the intervention being evaluated, but it may not be suitable for evaluation purposes (for instance, it may be well suited for acquiring funding or communication purposes). Something more evaluable is needed, such as developing nested ToCs to unpack the complexity of the intervention, with careful thought given to the causal assumptions at play.

Developing "good" ToCs is itself a challenge, but equally it is often a serious challenge to bring on board those who "own" the existing ToC and may not want to see a new ToC brought into play. Koleros and Mayne (2019) discuss handling this situation.

\section{Behaviour-Change ToC Models}

Most interventions involve changing the behaviour of one or more actor groups, so behaviour change needs to be a key focus (Earl, Carden, \& Smutylo, 2001). The detailed ToCs needed for CA can be based on the generic behaviour-change ToC model, shown in Figure 1 (Mayne, 2017, 2018). The model is a synthesis of social 
science research on behaviour change by Michie, Atkins, and West (2014), which argues that behaviour (B) is changed through the interaction of three necessary elements: capabilities (C), opportunities (O), and motivation (M). Hence the name: the COM-B model.

The COM-B ToC model has proven very useful for building robust nested ToCs and for undertaking contribution analysis, because it is quite intuitive and is based on a synthesis of empirical evidence on behaviour change. It is especially helpful in explaining how behaviour changes were brought about. That is, the COM-B model is a model of the mechanisms ${ }^{4}$ at work in bringing about behaviour change and thus provides the basis for inferring causality about behaviour change.

A number of authors who have used contribution analysis in complex settings have noted, though, that it can be quite data- and analysis-demanding, when one has to work with a large number of nested ToCs (Delahais \& Toulemonde, 2012; Freeman, Mayhew, Matsinhe, \& Nazza, 2014; Noltze et al., 2014; Schmitt and Beach (2015) make a similar note regarding process tracing, which is closely related to CA (Befani \& Mayne, 2014).

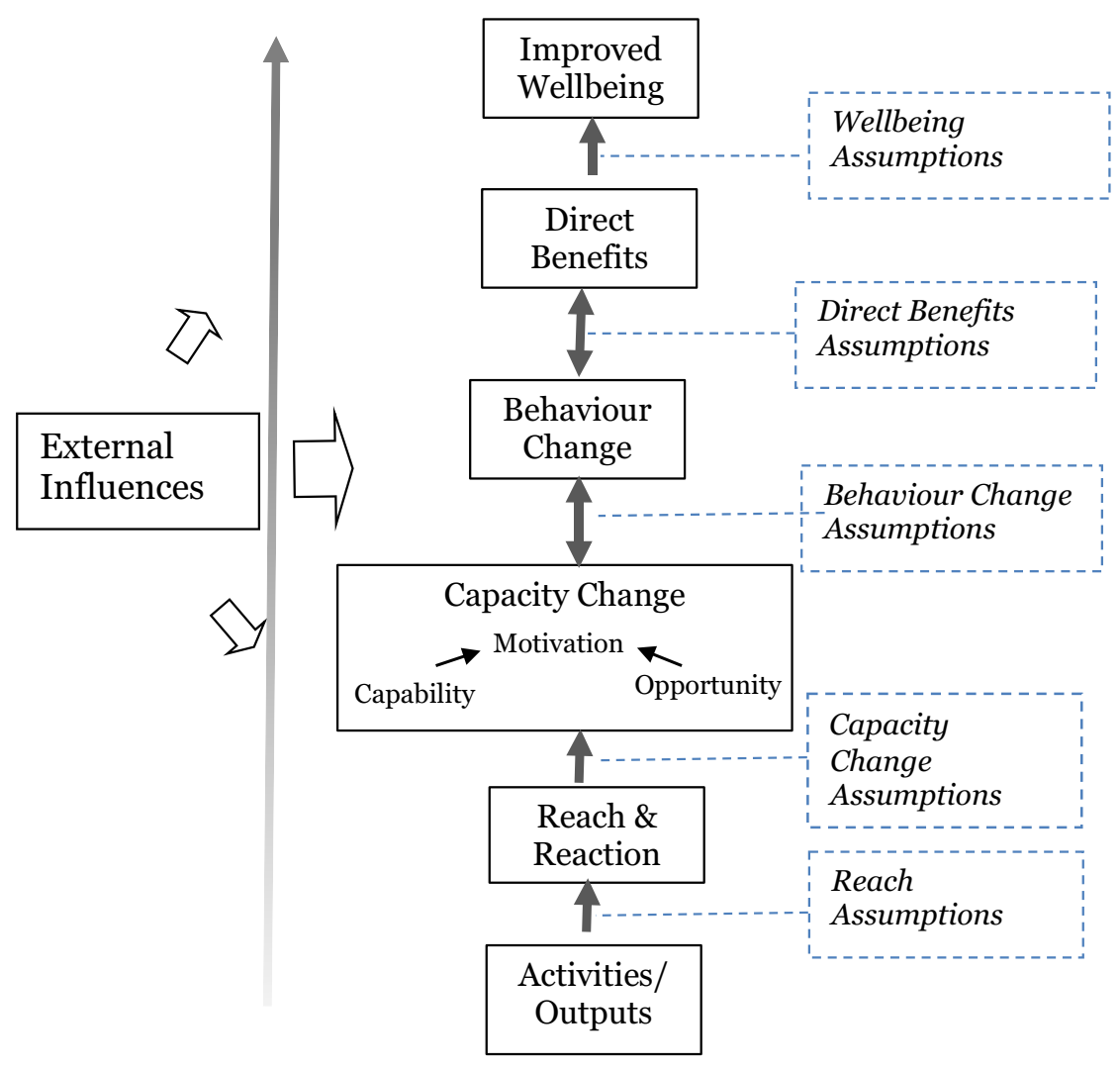

Figure 1. The COM-B Theory of Change model 
With that in mind, intermediate level ToCs would be useful-more than the overview ToC but less detailed than an operational nested ToC. This is where a simplified ToC could be useful. The idea of a simplified ToC is to develop a less complex ToC in the context of a contribution analysis, especially when there may be quite a few pathways to analyze. So, for example, rather than the more detailed generic behaviour-change ToC (Figure 1), we might have, more simply, activities/ outputs, behaviour change, direct benefits, and impact (Figure 2) as the pathway ToC. Figure 2 shows the essence of the pathway getting from activities/outputs to impact, explicitly identifying results that are usually straightforward to measure. The associated causal link assumptions would normally include the following assumptions:

- the intended target groups were reached, and

- $\quad$ adequate improvements in capabilities, opportunities, and motivation were achieved.

In setting out the causal link assumptions, a detailed nested ToC for the pathway is almost essential for their identification. The aim would be to have a minimum number of higher-level assumptions in the simplified ToC, perhaps arrived at by aggregating assumptions from the more detailed ToC.

Figure 2 shows one model for a simplified ToC. Even simpler pathways could be developed, such as dropping the behaviour change box, or the direct benefit

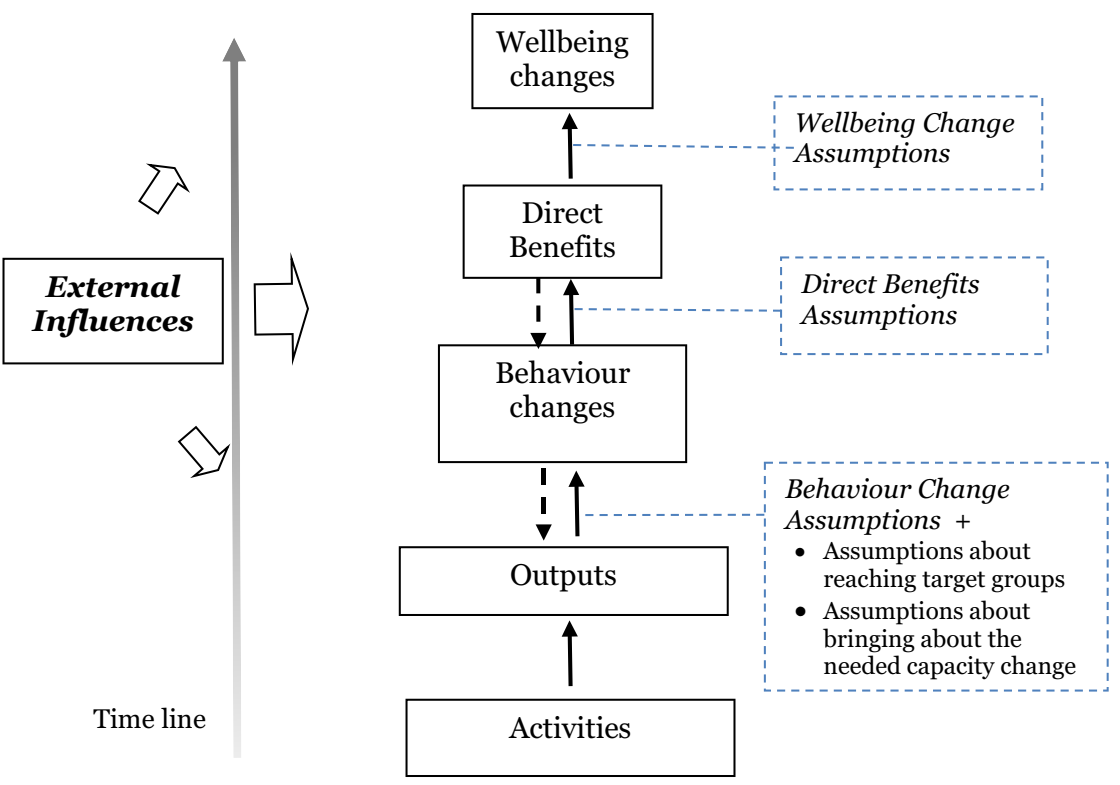

Figure 2. A simplified COM-B Theory of Change 
box. Then the pathway assumptions would have to include behaviour change and direct benefits, respectively, in order to keep those in the model.

Simplified ToCs would reduce the amount of data required to carry out a contribution analysis to determine if the intervention had made a contribution or not. However, in order to understand why the intervention did or did not work, one would need to focus on the behaviour-change level. But determining why the expected behaviour changes did not come about, for instance, can be done retrospectively, asking those involved about reach and capacity change (capabilities, opportunities, and motivation).

Experience to date does suggest the need to first develop a detailed nested ToC, and then the simplified version. In this way it becomes clear what is being suppressed in the simplified $\mathrm{ToC}$ and needs to be kept in mind, even though the simplified $\mathrm{ToC}$ would actually be used in Contribution Analysis.

\section{HOW MUCH OF A CONTRIBUTION?}

There remains in CA a desire to say something about the quantitative size of the contribution a causal factor is making. Budhwani and McDavid (2017, p. 20) talk about measuring the degree of contribution so that the CA can reach findings similar to cost-benefit analysis. This is not possible because of the nature of complex causality. There are multiple causal factors at work, and it is packages of necessary causal factors that bring about change, not any individual factor. Although others have attempted to examine the issue of estimating size effects within contribution analysis (Ton et al., 2019), CA does not, on its own, estimate the size or indeed the relative importance of the causal factors at work.

But exploring the relative importance question is possible (Mayne, 2019). There is a need, then, to carefully decide (a) which causal factors one wants to compare and (b) how one wants to interpret "importance." A variety of perspectives are possible: perceived importance, the roles played by the factors, the funds expended, and the extent of the constraints to change. All are plausible ways of assessing the relative importance of causal factors.

\section{INFERRING CAUSALITY: DEMONSTRATING CONTRIBUTION CLAIMS}

CA aims to result in claims about the contribution made by an intervention to observed results. A first question, then, is which results? In looking at an intervention and its $\mathrm{ToC}$, it is clear that there could be a number of interesting contribution claims, namely, claims associated with any of the results along the impact pathway. Contribution claims for early results would probably be quite easily established, while more distant outcomes and impact are likely to present more of a challenge. But it would be important to identify just which contribution claims were of prime interest. 
And of course, claims for more distant results need to be built on credible claims for the earlier pathway results. Hence the need to consider approaches to verifying a single causal link in a ToC. In a more complex intervention there would be several different pathways to impact, each with its own ToC. And often, it is useful to know if each of these pathways contributed to the success (or not) of the intervention. For example, in the case where actor-based ToCs have been developed for the intervention, it is of considerable interest to understand how and why the various actor groups contributed to bring about results.

\section{Causal Inference Analysis}

Key to credible contribution claims are credible arguments inferring causality-the logic and evidence used to justify a causal link-which would be used in Step 4 to assess the contribution story to date. An evidence-based contribution claim has two parts:

1. The intervention (or a component) contributed to an observed changeit played a positive role in bringing about change, and

2. It did so in the following manner ...

Showing that the intervention was a contributory cause accomplishes both of these aims: the intervention is part of a causal package that was sufficient to bring about the change-which explains how the change was brought about (2), and that the intervention was a necessary part of the causal package (1), and hence a causal factor in bringing about the change. Process tracing is a useful alternative way for getting at (1), but it does not provide the information needed for (2).

Befani and Mayne (2014) and Befani and Stedman-Bryce (2016) have noted correctly that while CA seeks to verify the causal links in a theory of change, previous discussions (Mayne, 2011, 2012) do not say much about how to go about doing the verification. Yet this is a key step and more of a challenge when examining complex interventions. This article looks more closely at making these causal inferences and builds on the approach of process tracing and related insights on causality, arguing the need for solid causal narratives.

In the traditional CA approach, showing that the intervention was a contributory cause and hence made a difference-that is, contributed to an observed impact and how it did so-requires demonstrating that

- the theory of change (the causal package) was sufficient, and

- the intervention activities were an essential part of the causal package, and hence a causal factor in bringing about change.

Sufficiency is demonstrated by showing that each causal link in the theory of change (ToC) with its assumptions was realized. Sufficiency was always a weak point in the argument, and I would now say that data showing the ToC was realized is not enough. One needs in addition to build credible causal narratives for the ToC. This picks up a key point made by Pearl and Mackenzie (2018) in their 
The Book of Why, namely that statistics alone are not enough to infer causality; one also needs good explanatory causal theory. As mentioned previously, good ToCs are often based on some social science theory and not just the thoughts of a program team, so that they can provide the basis for solid causal explanations. What is needed is good causal reasoning (Davidson, 2013).

Let me first note again that CA is expected to be done on a reasonably robust ToC, and many of the criteria for robustness are indeed criteria for inferring causality, forming the elements of a credible causal narrative. Table 1 sets out four tools for inferring causality, all of which are embedded in a robust ToC and described in more detail below.

The evidence tools in Table 1 can be used to build credible causal narratives. Causal narratives provide the argument and evidence related to how the causal factors at work played a positive role in bringing about change. They explain the how a causal link worked, or the causal mechanisms at play. In Table 1, the "Robust ToC \#" values are references to the robust criteria in Mayne (2017).

\section{Causal Inference Evidence Tools}

\section{Checking that Change Occurred}

1. Verifying the ToC. With a robust ToC, verifying that the pathway results and associated assumptions were realized lays the basis for the plausibility of a contribution claim. As Weiss (1995, p. 72) argues, "Tracking the micro-stages of the effects as they evolve makes it more plausible that the results are due to program activities and not to outside events or artifacts of the evaluation, and that the results generalize to other programs of the same type." Verifying the ToC provides the empirical evidence on which causal narratives are built. If aspects of the ToC cannot be verified, then causal claims cannot be made about those aspects.

The next three tools are hoop tests used in process tracing. If the verified ToC does not reflect them, then causality is unlikely. However, confirming these three tests does not confirm causality, as there may be other causal factors at work.

\section{Hoop Tests for Confirming Plausibility}

2. Logical and plausible time sequence of results and assumptions. The evidence sought here is that

- $\quad$ the results along a pathway were realized in a logical time sequence (i.e., cause preceded effect along the causal chain);

- the assumptions for each causal link were realized after the preceding result, i.e., were pre-events and conditions for the subsequent result; and

- the timing of when the results were realized was plausible and consistent with the ToC timeline.

This may seem like an obvious criterion, but in practice it can prove quite useful. Too often, for example, ToCs do not have a timeline and hence the third component of the criterion cannot be applied. It can easily be the case that a result 
Table 1. Evidence for inferring causality

\begin{tabular}{|c|c|c|}
\hline Tools & References & Comment \\
\hline \multicolumn{3}{|c|}{ Checking that change occurred } \\
\hline $\begin{array}{l}\text { 1. Verifying pathway } \\
\text { and assumptions, } \\
\text { including at-risk } \\
\text { assumptions }\end{array}$ & $\begin{array}{l}\text { - Robust ToC \#9 } \\
\text { - Contribution Analysis } \\
\text { - Weiss (1995) }\end{array}$ & $\begin{array}{l}\text { Are the pathway and assumptions } \\
\text { verified? This forms the evidence } \\
\text { base for making the contribution } \\
\text { claims. }\end{array}$ \\
\hline
\end{tabular}

Hoop tests for confirming plausibility

2. Logic and plausible - Robust ToC \#3 : timing Needed to explain causality.

time sequence

- Davidson (2009)

- Robust ToC \#4: Logical coherence

$\begin{array}{ll}\begin{array}{l}\text { 3. Reasonable effort } \\ \text { expended }\end{array} & \begin{array}{l}\text { Robust ToC \#11: level } \\ \text { of effort } \\ \text { - Davidson (2009) }\end{array} \\ \begin{array}{ll}\text { 4. Expect-to-see } \\ \text { effects realized }\end{array} & \begin{array}{l}\text { Process tracing: hoop } \\ \text { test }\end{array}\end{array}$

Link: Are assumptions pre-events and conditions for the result?

ToC: Is sequence of results plausible? Is the timing of the occurrence of the results plausible?

Is it reasonable that the level of effort expended will deliver the results?

If effects not seen, causality very unlikely. But effects might have other causes.

\section{Building the causal narrative}
5. Causal packages - Robust ToC \#10: A are sufficient
Is it reasonable that the collection of causal package factors is sufficient to bring about the result?
Are the mechanisms at work identified?
Have the barriers to change been addressed?

Confirming a causal factor
6. Some unique effects observed
- Process tracing: smoking gun tests
Result only possible if intervention is the cause.

was not realized because not enough time has elapsed. Conversely, if a result has indeed appeared but earlier than expected, it may suggest something other than the intervention at work. Furthermore, confirming that the assumptions were realized in a timely fashion means that the basis for the causal narrative for the link is sound. Taken together, the three points above argue that the causal link is quite plausible.

3. Reasonable effort expended. Again this is a plausibility test. If, in implementation, the size of the actual intervention, including the efforts of any partners, 
appears quite small in comparison to the observed results, then a contribution claim may seem implausible (Davidson, 2009).

4. Expected-to-see effects realized. This is the process-tracing hoop test (Punton \& Welle, 2015) whereby if the causal link has worked, then there are effects, often secondary effects, that one would expect to see. If those effects are not realized, then the causal link is doubtful.

\section{Building the Causal Narrative}

5. Causal packages are sufficient. This is the essential tool in building the causal narrative. We are trying to build an argument that the causal link between one result (R1) along an impact pathway - the cause — and its subsequent result (R2) the effect - worked. We would have shown that R1 and R2 did occur, as did the associated causal link assumptions. The set of assumptions in particular set out the framework for the argument, for the causal "story." In bringing about R2, one can imagine various constraints or barriers to change. The assumptions are events and conditions that are expected to overcome these barriers. This can be a useful way to develop the causal narrative.

A related approach is using causal mechanisms. Realist evaluation (Westhorp, 2014) argues that causality can be inferred by identifying and explaining the causal mechanisms at work and the contexts in which the intervention occurs. In a ToC approach, the context and the mechanisms at work are captured by the causal link assumptions.

Schmitt and Beach (2015) have claimed that ToCs "hide" the mechanism at work. While the realist causal mechanisms are not explicit in many ToC models and hence CA, CA uses a different paradigm to conceptualize causality, namely causal packages. Further, the causal mechanisms can often be readily identified by working through the causal package at work. Delahais and Toulemonde (2017, p. 385), in discussing their contribution analysis work, make this link:

In the process of translating the "framing pathway" into a "framing mechanism," we may consider that we have just refined the description of the causal package, i.e. deepened the exercise without changing its nature. We have often had this impression while reading illustrations of the concept of mechanism .... In fact the very change in the nature of the exercise occurs when the mechanism is given a name and referred to the literature, i.e. when we assume that it remains the same in different contexts and then acquires its generalization potential.

That is, the advantage of using causal mechanisms is that they refer to more general causal forces at work, as referred to in the literature, and hence provide common-sense logical explanations of causality. Let me note in particular that the social science research-based COM-B ToC model explicitly identifies the causal mechanisms at work, namely capability, opportunity, and motivation to bring about behaviour change.

The bottom line is to set out a sound and valid argument- a causal narrativeof why the causal package at work did indeed contribute to R2. 


\section{Confirming a Causal Factor}

6. Unique effects realized. This is the process-tracing smoking gun test for a causal factor. Unique effects with respect to a specific causal factor are effects that can be realized only if the causal factor was indeed part of the causal package bringing about change (Befani \& Mayne, 2014; Punton \& Barnett, 2018). If they are observed, then this is strong evidence that the causal factor played a positive causal role in bringing about $\mathrm{R} 2$. But note that this test does not provide evidence of how the change was brought about, that is, what the other factors in the causal package are.

\section{GENERALIZING CA FINDINGS}

Contribution analysis shows that an intervention in a specific location contributed to an observed result and how it did so. What might be said about the intervention implemented in a different location? This is the issue of external validity or generalization of CA findings.

If the intervention ToC worked in the new location, would it play the same positive causal role there? To conclude this, one would need to show that it was likely that in the new location

- the intervention could deliver the same (or quite similar) outputs,

- the causal link assumption would be realized, and

- the causal narratives would remain valid.

The likelihood of each of these could be assessed. To the extent that higher-level causal assumptions have been used in the ToC, such as when causal mechanisms have been identified, then the argument that the causal narratives remain valid will be stronger. In the nutrition example mentioned earlier, a key assumption needed was that mothers control food distribution in the household (an assumption that was missed initially). However, the more general causal assumption is that there is a need to education the person(s) in power in the household-which might not be the mother-a higher-level assumption.

One would need to carefully assess the conditions outlines above to produce a finding about the generalizability of an intervention. Cartwright and Hardie (2012, p. 7) argue that generalizing follows if, in a new location, the intervention played the same causal role and the support factors (the causal link assumptions) are in place. This is the same rationale as the CA argument above, using slightly different terms.

Clearly, if there is something very unique about the original location in some causal link assumptions, then generalizing is unlikely to be possible.

\section{SO WHITHER CONTRIBUTION ANALYSIS?}

Contribution analysis was set out some years ago as a set of general steps to take in addressing causality. As such, over a number of years it led to a variety of ways 
of operationalizing the concepts and principles, with numerous suggestions being made for applying CA in specific cases. This has all been for the good. There have also been numerous articles raising legitimate questions about CA and its application. In this article I have tried to look back at how CA has been applied and consider the concerns that have been expressed.

In the last few years, I have seen a significant rise in applications of CA, particularly as applied to complex settings, which are becoming more common. And indeed, given that it assumes that multiple causal factors and interventions can play a contributory role, it can be well suited to address causality in those settings, especially using nested ToCs. I expect to see more and more applications of CA in a variety of settings. But there is a need to be clear about what contribution analysis can and cannot do.

Contribution analysis is not a quick-and-dirty approach to addressing causality. On the downside, (1) it often does require a substantial amount of data, along with rigorous thinking, (2) it requires reasonably robust theories of change, and (3) it cannot determine how much of an outcome result can be attributed to an intervention.

On the other hand, it offers several advantages: (1) it can be used to make causal inferences when experimental and quasi-experimental designs are not possible, or not needed/desired; (2) it explores why and how an intervention has influenced change, and for whom; (3) it can be part of a mixed-method approach to an evaluation, such as when using comparative groups to assess how much change has occurred; (4) it allows for making causal inferences about the intervention without necessarily examining external causal factors; and (5) it addresses cases where there are numerous causal factors at work by assessing contributory causes leading to credible contribution claims.

Overall, CA has been found to be a practical way to explore causal relationships and to better understand how changes have been brought about, and for whom.

\section{NOTES}

1 For a discussion on different perspectives on causality, see Befani's Appendix in Stern et al. (2012).

2 "Likely necessary" allows for a probabilistic interpretation of an assumption (Mahoney, 2008, p. 421). See Mayne (2015, p. 126) for a discussion.

3 That is, they are an Insufficient but Necessary part of a condition that is itself Unnecessary but Sufficient for the occurrence of the effect (Mackie, 1974). See Mayne, (2012, p. 276) for a discussion of these INUS conditions.

4 Realist evaluations use the concept of mechanisms to infer causality (Pawson \& Tilley, 1997; Westhorp, 2014).

\section{REFERENCES}

Befani, B., \& Mayne, J. (2014). Process tracing and contribution analysis: A combined approach to generative causal inference for impact evaluation. IDS Bulletin, 45(6), 17-36. https://doi.org/10.1111/1759-5436.12110 
Befani, B., \& Stedman-Bryce, G. (2016). Process tracing and Bayesian updating for impact evaluation. Evaluation, 23(1), 42-60. https://doi.org/10.1177/1356389016654584

Buckley, A. P. (2016). Using Contribution Analysis to evaluate small \& medium enterprise support policy. Evaluation, 22(2), 129-148. https://doi.org/10.1177/1356389016638625

Budhwani, S., \& McDavid, J. C. (2017). Contribution analysis: Theoretical and practical challenges and prospects for evaluators. Canadian Journal of Program Evaluation, 32(1), 1-24. https://doi.org/10.3138/cjpe.31121

Buregeya, J. M., Brousselle, A., Nour, K., \& Loignon, C. (2017). Comment évaluer les effets des évaluations d'impact sur la santé : le potentiel de l'analyse de contribution. Canadian Journal of Program Evaluation, 32(1), 25-45. https://doi.org/10.3138/cjpe.31151

Byrne, D. (2013). Evaluating complex social interventions in a complex world. Evaluation, 19(3), 217-228. https://doi.org/10.1177/1356389013495617

Cartwright, N., \& Hardie, J. (2012). Evidence-based policy: Doing it better. A practical guide to predicting if a policy will work for you. Oxford, England: Oxford University Press.

Davidson, E. J. (2009). Causation inference: Nuts and bolts. A Mini Workshop for the ANZEA Wellington branch. Welington, New Zealand. Retrieved from http://realevaluation. com/pres/causation-anzea09.pdf

Davidson, E. J. (2013). Understanding causes and outcomes of impacts. BetterEvaluation coffee break webinars. Retrieved from https://www.betterevaluation.org/events/ coffee_break_webinars_2013\#webinarPart5

Davies, R. (2012). Criteria for assessing the evaluability of Theories of Change. Rick on the road [blog]. Retrieved from http://mandenews.blogspot.com/2012/04/criteria-forassessing-evaluablity-of.html

Delahais, T., \& Toulemonde, J. (2012). Applying contribution analysis: Lessons from five years of real life experience. Evaluation, 18(3), 281-293. https://doi.org/10. $1177 / 1356389012450810$

Delahais, T., \& Toulemonde, J. (2017). Making rigorous causal claims in a real-life context: Has research contributed to sustainable forest management? Evaluation, 23(4), 370-388. https://doi.org/10.1177/1356389017733211

Douthwaite, B., Mayne, J., McDougall, C., \& Paz-Ybarnegaray, R. (2017). Evaluating complex interventions: A theory-driven realist-informed approach. Evaluation, 23(3), 294-311. https://doi.org/10.1177/1356389017714382

Downes, A., Novicki, E., \& Howard, J. (2018). Using the contribution analysis approach to evaluate science impact: A case study of the national institute for occupational safety and health. American Journal of Evaluation, 40(2), 177-189. https://doi. org/10.1177/1098214018767046. Medline:30518992

Dybdal, L., Nielsen, S. B., \& Lemire, S. (2010). Contribution analysis applied: Reflections on scope and method. Canadian Journal of Program Evaluation, 25(2), 29-57.

Earl, S., Carden, F., \& Smutylo, T. (2001). Outcome mapping. Ottawa, ON: International Development Research Centre.

Freeman, T., Mayhew, S., Matsinhe, C., \& Nazza, D. A. (2014). Evaluation of the Danish strategy for the promotion of sexual and reproductive health and rights 2006-2013Pathways to change in SRHR: Synthesis report. Ministry of Foreign Affairs of Denmark. 
Retrieved from http://www.netpublikationer.dk/um/14_evaluation_2014_03/Pdf/ evaluation_2014_03.pdf

Gates, E., \& Dyson, L. (2017). Implications of the changing conversation about causality for evaluators. American Journal of Evaluation, 38(1), 29-46. https://doi. org/10.1177/1098214016644068

Gerrits, L., \& Verweij, S. (2015). Taking stock of complexity in evaluation: A discussion of three recent publications. Evaluation, 21(4), 481-491. https://doi. org/10.1177/1356389015605204

Kane, R., Levine, C., Orians, C., \& Reinelt, C. (2017). Contribution analysis in policy work: Assessing advocacy's influence. Centre for Evaluation Innovation. Retrieved from https://www.evaluationinnovation.org/wp-content/uploads/2017/11/ContributionAnalysis_0.pdf

Koleros, A., \& Mayne, J. (2019). Using actor-based theories of change to conduct robust contribution analysis in complex settings. Canadian Journal of Program Evaluation, 33(3), 292-315. https://doi.org/10.3138/cjpe.52946

Lemire, S. T., Nielsen, S. B., \& Dybdal, L. (2012). Making contribution analysis work: A practical framework for handling influencing factors and alternative explanations. Evaluation, 18(3), 294-309. https://doi.org/10.1177/1356389012450654

Mackie, J. L. (1974). The cement of the universe: A study of causation. Oxford, England: Oxford University Press.

Mahoney, J. (2008). Toward a unified theory of causality. Comparative Political Studies, 41(4/5), 412-436. https://doi.org/10.1177/0010414007313115

Mayne, J. (2001). Addressing attribution through contribution analysis: Using performance measures sensibly. Canadian Journal of Program Evaluation, 16(1), 1-24. Retrieved from https://evaluationcanada.ca/system/files/cjpe-entries/16-1-001.pdf

Mayne, J. (2011). Contribution analysis: Addressing cause and effect. In R. Schwartz, K. Forss, \& M. Marra (Eds.), Evaluating the complex (pp. 53-96). New Brunswick, NJ: Transaction Publishers.

Mayne, J. (2012). Contribution analysis: Coming of age? Evaluation, 18(3), 270-280. https://doi.org/10.1177/1356389012451663

Mayne, J. (2015). Useful theory of change models. Canadian Journal of Program Evaluation, 30(2), 119-142. https://doi.org/10.3138/cjpe.230

Mayne, J. (2017). Theory of change analysis: Building robust theories of change. Canadian Journal of Program Evaluation, 32(2), 155-173. https://doi.org/10.3138/cjpe.31122

Mayne, J. (2018). The COM-B theory of change model. Retrieved from https://www.researchgate.net/publication/323868561_The_COMB_ToC_Model4

Mayne, J. (2019). Assessing the relative importance of causal factors. CDI Practice Paper 21. Brighton, England: IDS. Retrieved from https://opendocs.ids.ac.uk/opendocs/ handle/123456789/14647

Mayne, J. (Forthcoming). Realistic commissioning of impact evaluations: Getting what you ask for? In A. Paulson \& M. Palenberg (Eds.), Evaluation and the pursuit of impact. Abingdon, England: Taylor and Francis. 
Mayne, J., \& Johnson, N. (2015). Using theories of change in the CGIAR Research Program on Agriculture for Nutrition and Health. Evaluation, 21(4), 407-428. https://doi. org/10.1177/1356389015605198

Michie, S., Atkins, L., \& West, R. (2014). The behaviour change wheel: A guide to designing interventions. London, England: Silverback Publishing. Retrieved from http://www. behaviourchangewheel.com/

Noltze, M., Gaisbauer, F., Schwedersky, T., \& Krapp, S. (2014). Contribution analysis as an evaluation strategy in the context of a sector-wide approach: Performance-based health financing in Rwanda. African Evaluation Journal, 2(1), 8 pp. Retrieved from http://www.aejonline.org/index.php/aej/article/view/81

Palladium. (2015). Independent evaluation of the Security Sector Accountability and Police Reform Programme: Final evaluation report. DFID. Retrieved from http://r4d.dfid.gov. $\mathrm{uk} / \mathrm{pdf} /$ outputs/SSAPRP-DRC/SSAPR_Complete_Impact_Evaluation_Rep_FinalEng.pdf

Pawson, R., \& Tilley, N. (1997). Realistic evaluation. London, England: SAGE.

Paz-Ybarnegaray, R., \& Douthwaite, B. (2016). Outcome evidencing: A method for enabling and evaluating program intervention in complex systems. American Journal of Evaluation, 38(2), 275-293. https://doi.org/10.1177/1098214016676573

Pearl, J., \& Mackenzie, D. (2018). The book of why: The new science of cause and effect. New York, NY: Basic Books.

Punton, M., \& Barnett, C. (2018). Contribution analysis and Bayesian confidence updating: A brief introduction. Itad briefing paper. Retrieved from https://itad.com/wp-content/ uploads/2019/06/CDC-Brief-contribution-analysis-and-Bayesian-Updating.pdf

Punton, M., \& Welle, K. (2015). Straws-in-the-wind, hoops and smoking guns: What can process tracing offer to impact evaluation? CDI Practice Paper, No. 10. Centre for Development Impact. Retrieved from http://opendocs.ids.ac.uk/opendocs/bitstream/ handle/123456789/5997/CDIPracticePaper_10.pdf?sequence=1

Riley, B. L., Kernoghan, A., Stockton, L., Montague, S., Yessis, J., \& Willis, C. D. (2018). Using contribution analysis to evaluate the impacts of research on policy: Getting to "good enough." Research Evaluation, 27(1), 16-27. https://doi.org/10.1093/reseval/ rvx037. Retrieved from https://academic.oup.com/rev/article/27/1/16/4554784

Schmitt, J., \& Beach, D. (2015). The contribution of process tracing to theory-based evaluations of complex aid instruments. Evaluation, 21(4), 429-447. https://doi. org/10.1177/1356389015607739

Stern, E., Stame, N., Mayne, J., Forss, K., Davies, R., \& Befani, B. (2012). Broadening the range of designs and methods for impact evaluations. DFID Working Paper, 38. London, England: DFID. Retrieved from http://r4d.dfid.gov.uk/Output/189575/

Ton, G. (2017). Contribution analysis of a Bolivian innovation grant fund: Mixing methods to verify relevance, efficiency and effectiveness. Journal of Development Effectiveness, 9(1), 120-143. http://doi.org/10.1080/19439342.2016.1231702

Ton, G., Mayne, J., Delahais, T., Morell, J., Befani, B., Apgar, M., \& O’Flynn, P. (2019). Contribution analysis and estimating the size of effects: Can we reconcile the possible with the impossible? CDI Practice Paper, Number 20. Centre for Development Impact. 
Retrieved from https://www.cdimpact.org/publications/contribution-analysis-andestimating-size-effects-can-we-reconcile-possible-impossible

Weiss, C. H. (1995). Nothing as practical as good theory: Exploring theory-based evaluation for comprehensive community initiatives for children and families. In J. P. Connell, A. C. Kubisch, L. B. Schorr, \& C. H. Weiss (Eds.), New approaches to evaluating community initiatives: Volume 1: Concepts, methods and contexts (pp. 65-92). Washington, DC: The Aspen Institute.

Westhorp, G. (2014). Realist impact evaluation: An introduction. Methods Lab. Retrieved from http://www.odi.org/sites/odi.org.uk/files/odi-assets/publications-opinionfiles/9138.pdf

White, H. (2009). Theory-based impact evaluation: Principles and practice. Working Paper 3. International Initiative for Impact Evaluation (3ie). Retrieved from https:// www.3ieimpact.org/sites/default/files/2017-11/Working_Paper_3.pdf

Wilson-Grau, R., \& Britt, H. (2012). Outcome harvesting. Retrieved from http://www. outcomemapping.ca/resource/resource.php?id=374

\section{AUTHOR INFORMATION}

John Mayne is an independent advisor on public sector performance. Over the past 13 years he has focused largely on international development evolution and results-based management work. 